\title{
Ultra-High Power Density Magnetic-less DC/DC Converter Utilizing GaN Transistors
}

\author{
Georgios Kampitsis, Remco van Erp, and Elison Matioli \\ École Polytechnique Fédérale de Lausanne (EPFL) \\ Power and Wide-Band-Gap Electronics Research (PowerLab) \\ CH-1015 Lausanne, Switzerland \\ Email: georgios.kampitsis@epfl.ch,remco.vanerp@epfl.ch, elison.matioli@epfl.ch
}

\begin{abstract}
In this paper, a high step-up magnetic-less DC/DC $\mathrm{nX}$ converter is designed and experimentally evaluated. GaN transistors are applied in a $\mathbf{n X}$ converter topology, yielding ultrahigh power density and high conversion efficiency. The absence of magnetic materials results in a constant efficiency throughout the power range; the power capability of the system is only limited by the ratings of the semiconductor devices. To effectively extract the dissipated power, a novel micro-fluidic heat sink is designed, based on microchannels fabricated on Silicon substrate and a laser-cut acrylic manifold. The developed liquid cooling heat sink yields a much smaller volume and higher cooling capability compared to conventional heat sinks. A $10 \mathrm{X}$ converter prototype with the integrated micro-fluidic heat sink is experimentally evaluated at various operating conditions and different flow rates for the cooling system. At a transferred power of $1.2 \mathrm{~kW}$ the converter exhibits an overall efficiency of $96 \%$, while occupying $260 \mathrm{~mL}$ of volume, resulting in 4.62 $\mathrm{W} / \mathrm{cm}^{3}$, a notable power density for such a high step-up DC/DC converter.
\end{abstract}

Keywords-DC/DC converter, GaN transistors, high power density, high efficiency, magnetic-less converter, liquid cooling

\section{INTRODUCTION}

The ever increasing need for system miniaturization and efficiency maximization in power conversion has led to a gradual trend towards replacing the conventional $\mathrm{Si}$ power devices with state-of-the-art wide bandgap (WBG) transistors. $\mathrm{GaN}$ is one of the most promising materials for future power conversion application, due to the large energy gap, superior breakdown field strength, and excellent electron saturation velocity, enabling high voltage and high frequency operation and allowing a significant reduction in size of the power converters [1]-[3].

In fact, the size and weight of modern power converters is dominated by the magnetic components. Even in high switching frequencies, a reduction in the size of transformers and inductors is prevented by the maximum permissible flux density in the core material and the increased winding losses, due to skin and proximity effects. In addition, magnetic cores exhibit a drastic decline in permeability with increasing temperatures [4], which hinders the efficient and reliable operation of power converters in high temperatures.

Magnetic-less converter topologies offer a way to fully exploit the outstanding characteristics of $\mathrm{GaN}$ technology for high power density converters. The first attempt for a high

This work was supported in part by the Swiss Office of Energy Grant No. SI501568-01 and in part by the European Research Council under the European Union's H2020 program/ERC Grant Agreement No. 679425. power (in the $\mathrm{kW}$ range) magnetic-less converter, with discrete Si devices, was performed in [5]. A generalized multilevel inverter phase leg was proposed, able to be used as a bidirectional, fixed-step DC/DC converter in dual-voltage automotive systems [6], with a disadvantage of a large number of transistors required. A modification of the generalized converter that achieves lower output voltage ripple and better capacitor balance was presented in [7], and a simplified topology was deduced from the generalized structure in [8][10], called the Flying Capacitor Multilevel DC/DC converter (FCMDC). Although the number of transistors was drastically reduced, the conduction losses still remained high. Additionally, this system is not modular and its reliability is compromised, since a malfunction of a single device inevitably leads to a complete system shutdown. To address these limitations, a multilevel modular capacitor clamped DC/DC converter (MMCCC) was proposed in [11]. A simple pulse width modulation (PWM) technique is required, where all transistors are driven either by a single pulse of $50 \%$ duty cycle, or by its complementary. The redundancy and flexibility to regulate the input-to-output voltage ratio of the MMCCC was demonstrated in [12]-[14]. The only major drawback of

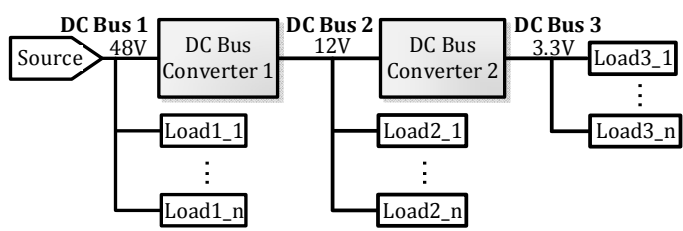

(a)

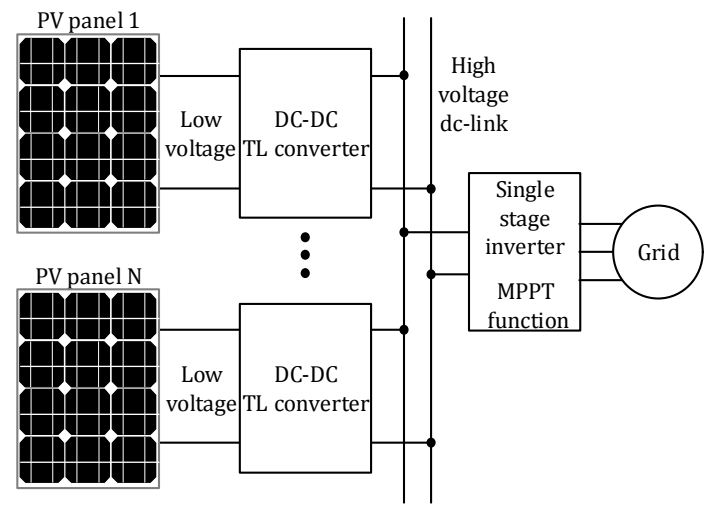

(b)

Fig. 1. Utilization of a magnetic-less DC/DC converter in (a) DC bus converter modules and (b) grid connected photovoltaic systems. 
this converter is the large component count.

The nX converter was first introduced in 2012, [15], and combines all the advantages of the MMCCC with a small number of required devices (only $2 \cdot N$ transistors are needed, where $N$ is the step-up ratio). It is a bidirectional, fixed-step $\mathrm{DC} / \mathrm{DC}$ converter with almost ripple-less output voltage, due to the complementary charging/discharging pattern of the output capacitors. All these features make the $\mathrm{nX}$ converter ideal for applications with high power density and high step-up conversion ratio requirements, such as DC bus converter modules for electric vehicles (EVs) or data centers, shown in Fig. 1(a) and renewable energy systems, e.g. per-panel microconverters, [16], as in Fig. 1(b).

The purpose of this work is to exploit the full advantage of magnetic-less converters for high-frequency, high-efficiency compact systems, utilizing state-of the-art GaN transistors. In the following Sections, the operating principles of the $\mathrm{nX}$ convert are discussed, the architecture of the proposed system is presented, including both the power electronics circuits and the micro-fluidic heat sink design, and a full experimental validation is performed.

\section{NX CONVERTER - OPERATING PRINCIPLES}

\section{A. Modes of Operation and Devices Stress}

The detailed schematic of a 3-cell $\mathrm{nX}$ converter (six times step-up ratio) is presented in Fig. 2(a), while Fig. 2(b) shows the $180^{\circ}$ complementary switching pattern of the transistors, corresponding to the two operating modes: transistors in continuous black line conduct in the first operating mode, while transistors in gray color conduct in the second operating mode. The same pattern can be extended for any number of cells, revealing the modularity of the system and the simplicity in controlling this converter. The different current paths formed at a given switching state are indicated with colored dashed lines in the same figure.

Provided that the current flowing through each path is equal to the output current, $I_{\text {out }}$, it can be easily observed that the current stress of the top and bottom rail transistors $\left(Q_{a}(i)\right.$ and $Q_{b}(i)$ respectively, where $\left.i=1,2, \ldots, N,\right)$ is $I_{D-a / b}(i)=I_{\text {out }}$ and the Positive and Negative transistors $\left(Q_{P}(i)\right.$ and $Q_{N}(i)$ respectively) is $I_{D-P / N}(i)=2 \cdot I_{\text {out }}$. An exception to this rule is the last cell, where $I_{D-P / N}(N)=I_{\text {out }}$.

The output capacitors of each cell, $\mathrm{C}_{\mathrm{a}}(i)$ and $\mathrm{C}_{\mathrm{b}}(i)$, are charged by connecting the capacitor of the previous cell $(i-1)$ in
TABLE I. Voltage AND CurRent Stress of the Semiconductor DEVICES.

\begin{tabular}{|c|c|c|c|}
\hline \multicolumn{2}{|c|}{ Parameter } & \multicolumn{2}{c|}{ Value } \\
\cline { 2 - 4 } & General Case & Exception \\
\hline Drin-Source & $\boldsymbol{P} / \boldsymbol{N}$ & $V_{\text {in }}$ & - \\
Voltage $\left(V_{D S}\right)$ & $\boldsymbol{a} / \boldsymbol{b}$ & $2 \cdot V_{\text {in }}$ & First Cell: $V_{D S}=V_{\text {in }}$ \\
\hline Drain & $\boldsymbol{P} / \boldsymbol{N}$ & $2 \cdot I_{\text {out }}$ & Last Cell: $I_{D}=I_{\text {out }}$ \\
\cline { 2 - 2 } Current $\left(I_{D}\right)$ & $\boldsymbol{a} / \boldsymbol{b}$ & $I_{\text {out }}$ & - \\
\hline
\end{tabular}

series with the input voltage, $V_{i n}$, as illustrated in Fig. 2(a) and described in (1). Knowing the capacitors' steady state voltage and the transistors' switching pattern, the voltage stress across the top and bottom rail power devices can be deduced and is equal to $2 \cdot V_{\text {in }}$. The only exception to this rule holds for the first cell, in which case $V_{D S-a / b}(1)=V_{i n}$. The Positive and Negative transistors of each cell form a bridge leg configuration that is always connected to the input power source, hence $V_{D S-P / N}(i)=$ $V_{i n}$. The voltage and current stress of all the power devices are summarized in TABLE I.

$$
V_{C}(i)=V_{C}(i-1)+V_{\text {in }}, \quad 1<\mathrm{i} \leq \mathrm{N}
$$

If properly tuned, the $\mathrm{nX}$ converter can be operated with zero current switching (ZCS). This can be achieved by matching the switching frequency with the resonance frequency of the capacitors and the circuit's parasitic inductances [17], [18]. To help match the resonance frequency and achieve ZCS operation, an additional small air-core inductor, $L_{s w}$, can be placed at the input. In this case the optimum switching frequency is given by (2).

$$
\omega_{r}=1 / \sqrt{\left(L_{\text {stray }}+L_{s w}\right) \cdot C_{a / b}}
$$

\section{B. Simulation Results}

To confirm the operating principles of the investigated converter and the maximum stress on each power device, simulations were performed using LTSpice. A 5-cell GaNbased $\mathrm{nX}$ converter was designed, utilizing the manufacturer's Level1 Spice models of the GS61008T, for the Positive and Negative transistors, and the GS66508T, for the top and bottom rail transistor. The converter was set to operate at $3 \mathrm{~kW}$ with an input voltage of $40 \mathrm{~V}$. In Fig. 3, the current waveform of $Q_{P}(5)$ is compared with that of $Q_{P}(2)$ and the drain-to-source voltage waveforms of $Q_{a}(1)$ is compared with that of $Q_{a}(2)$, to reveal the lower power stress of the first and last cell's transistors.

The simulation results are also a first indicator of the exceptional performance and the unique potential of the GaN-

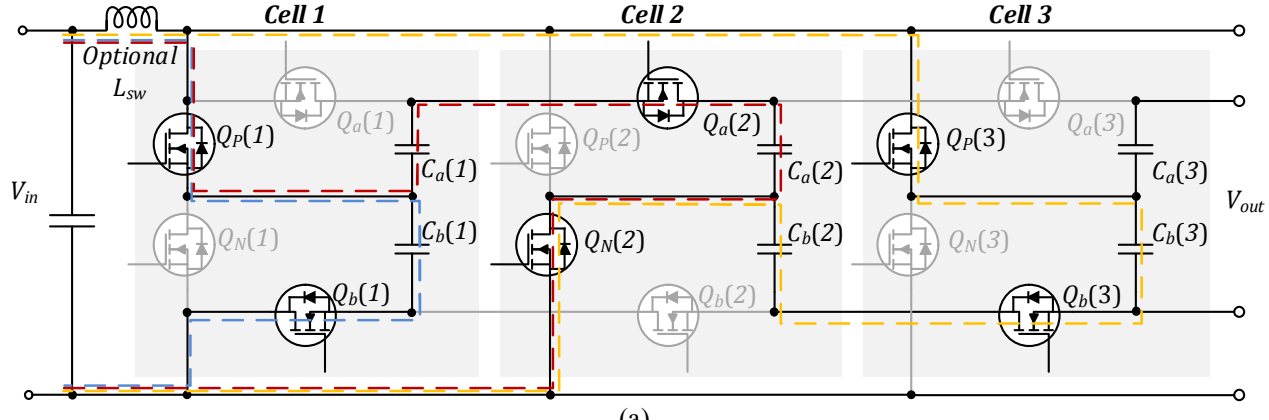

(a)

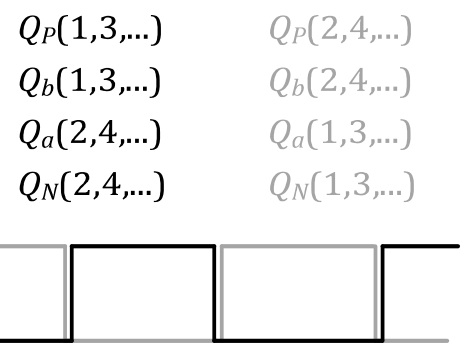

(b)

Fig. 2. (a) A 3-cell nX converter topology (6 times step-up ratio) and (b) switching pattern. 


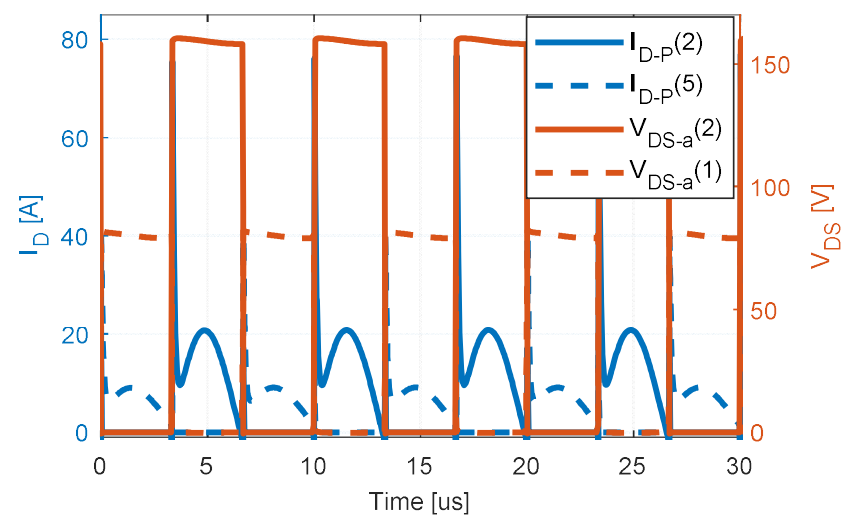

Fig. 3. LTSpice simulation results of the $\mathrm{nX}$ converter operating at $P_{i n}=3$ $\mathrm{kW}, V_{\text {in }}=40 \mathrm{~V}$ with ZCS. Voltage and current stress of the GaN power devices.

based magnetic-less converters. When the system operates in ZCS conditions, the calculated efficiency exceeds $98.5 \%$ at full load (3 kW). However, the simplified components' models (including the transistors, capacitors, interconnecting lines, etc.) do not represent the exact converter performance under all conditions and experimental evaluation follows in Section IV.

\section{GAN-BASED MAGNetiC-LeSs CONVERTER Design}

The developed all-GaN $10 \mathrm{X}$ converter prototype was designed in a split-board configuration in order to maximize the power transfer capability and optimize the cooling process, while keeping the volume to a minimum.

\section{A. Power Electronics Design}

The system consists of two separate printed circuit boards (PCBs): the drive board with black solder mask in Fig. 4(a) and the power board, depicted in white color in Fig. 4(b).

- The drive board incorporates all the low power ICs, including the microcontroller, the co-packed digital and power isolators - ISOW7842F and the driving circuits. This board is powered by a single micro-USB port.

- The power board contains $20 \mathrm{GaN}$ transistors, the switching capacitors and the power terminals. The $100 \mathrm{~V} / 90 \mathrm{~A}$ GS61008T were selected for all the transistors in bridge leg configuration, $Q_{P / N}(\mathrm{i})$, and the $600 \mathrm{~V} / 30 \mathrm{~A}$ GS66508T for the top and bottom rail transistors, $Q_{a / b}(\mathrm{i})$. This selection leads to a theoretical limitation of the output voltage to $1 \mathrm{kV}$ and the output current to $30 \mathrm{~A}$, resulting in high power density. All devices have thermal pads (connected to their source) at their top side for maximum heat extraction by means of an external heat sink. As can be seen in Fig. 4(b), one side of the power board was dedicated only for the GaN HEMTs so that the heat sink can be mounted freely, given the low profile of the GaN transistors. Four parallel connected multilayer ceramic capacitors (MLCC) of $2.2 \mathrm{uF}$ each, with extremely low internal series resistance (ESR) constitute the output capacitor of each cell. An external air-core inductor, $L_{s w}$, is also placed in series with the input voltage source to help achieve ZCS.

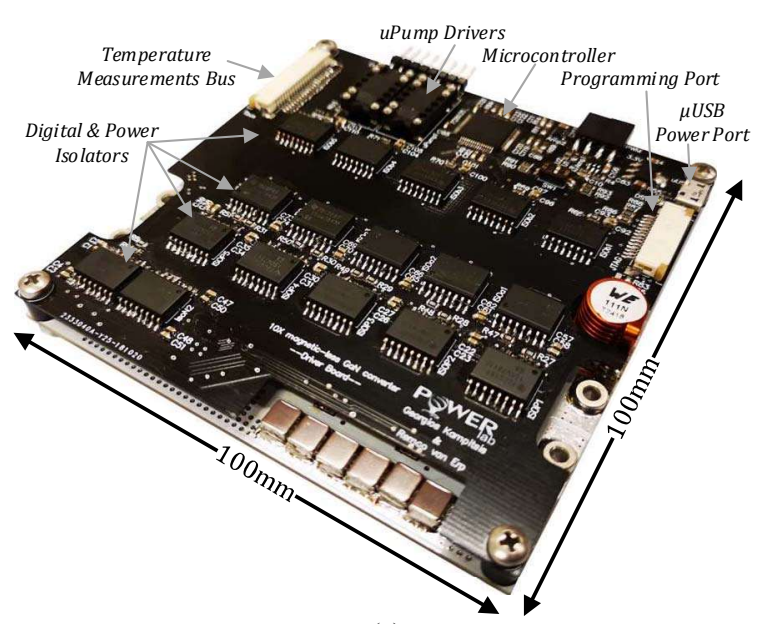

(a)
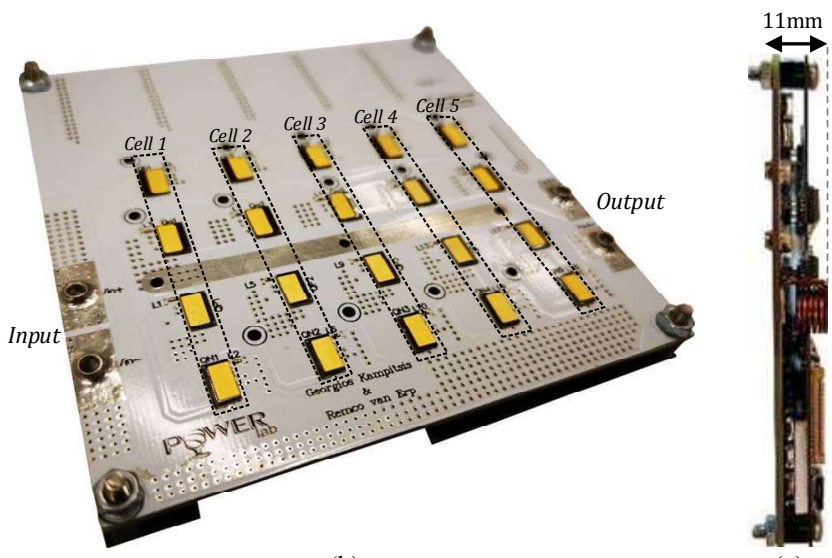

(b)

Fig. 4. Developed 10x magnetic-less DC/DC converter prototype. (a) Top side of the driver board, where the microcontroller and all digital and power isolators are placed, (b) bottom side of the power board containing all $20 \mathrm{GaN}$ HEMTs and (c) side view of the integrated system.

The two PCBs are connected via twenty $2 \times 2$ headers that transfer four signals for each individual transistor: power supply $V_{D D}(\mathrm{i})=5 \mathrm{~V}$, ground, $G N D(\mathrm{i})$, the gate signal, $P W M(\mathrm{i})$ and the temperature signal, $\operatorname{TEMP}(\mathrm{i})$, that is explained later in this section. The entire split-board configuration is just $100 \mathrm{~mm}$ $\mathrm{x} 100 \mathrm{~mm} \times 11 \mathrm{~mm}$, as depicted in Fig. 4(a) and (c), resulting in a total volume of $110 \mathrm{~mL}$. A complete list of the components used is given in TABLE II.

TABLE II. List of COMPONENTS USED IN THE DEVELOPED $\mathrm{nX}$ CONVERTER.

\begin{tabular}{|c|c|}
\hline Component & Part Number \\
\hline Positive/Negative transistors $\left(Q_{P / N}\right)$ & GS61008T \\
Top/Bottom rail transistors $\left(Q_{a / b}\right)$ & GS66508T \\
Switching capacitors $\left(C_{a / b}\right)$ & $2.2 \mathrm{uF} \mathrm{MLCC}$ \\
Soft switching inductor $\left(L_{s w}\right)$ & $111 \mathrm{nH}$ \\
Microcontroller & TMS320F28035 \\
Isolated power supply / Digital isolator & ISOW7842F \\
Gate driver & $\mathrm{LM} 5114$ \\
Gate resistors $\mathrm{R}_{\text {on }} / \mathrm{R}_{\text {off }}$ & $10 \Omega / 5.1 \Omega$ \\
Gate-source TVS diode & DF2B7AE,H3F \\
TTL thermocouple & TMP05B \\
\hline
\end{tabular}




\section{B. Thermal Management}

When designing power converters based on $\mathrm{GaN}$ technology, the PCB layout plays an important role for the operation and reliability of the system. In the proposed $\mathrm{nX}$ converter a $70 \mu \mathrm{m}$ thickness was selected for the copper traces in both sides of the power board. The copper traces can effortlessly conduct the required current and, at the same time, help spread the heat away from the GaN transistors. Thermal vias have been placed in close proximity to the power devices, which reduce the thermal resistance between the two PCB layers.

To continuously monitor the temperature of each transistor and avoid local hot-spot formation, a small thermocouple with a serial communication protocol (TTL) was placed right underneath each HEMT, on the other side of the power board PCB. This approach allows for a real time tracking of all transistor temperatures, even when a heat sink prevents visual inspection with an infrared (IR) camera. The temperature signal, TEMP(i), is isolated and transferred to an external highend microcontroller. The thermocouple's TTL signal, with a period of around $100 \mathrm{~ms}$ (variable with temperature), was sampled at a frequency of $50 \mathrm{kHz}$, leading to a measurement error of less than $0.05 \%$. After digital filtering, all temperature measurements were saved at a rate of 15 samples $/ \mathrm{min}$.

Cooling down GaN-based power converters is a major challenge, due to their increased heat fluxes as a result of the miniaturized footprint of the $\mathrm{GaN}$ power devises. To effectively address this problem, a novel silicon-based microchannel heat sink manifold is proposed in this work that combines the high heat extraction capabilities of microchannel liquid cooling in close contact with the hot spots, [19], with a low pressure drop by using a manifold to spread the liquid uniformly over the microchannel cold plates. An advantage of using this manifold is that the distance the liquid passes through these microchannels is minimized, reducing the pumping requirements of the heat sink, which allows the use of small, energy efficient micropumps. For maximum efficiency

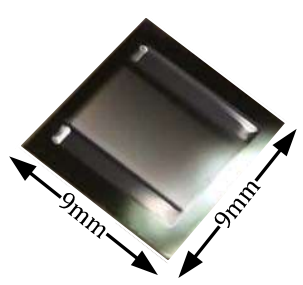

(a)

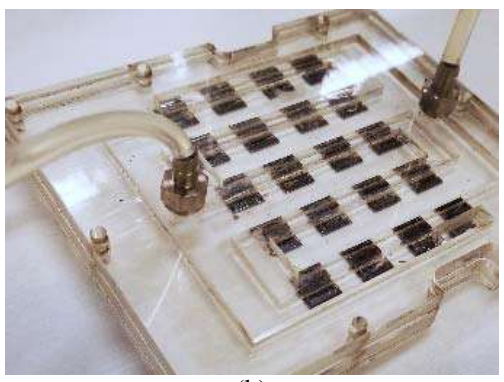

(b)
Fig. 5. (a) A single Si cold plate with embedded microchannels and (b) PMMA manifold that spreads the liquid to the twenty Si-chips.

and compatibility the liquid cooling heat sink was co-designed with the power electronics circuits.

The heat sink consists of twenty deep-reactive-ion-etched (DRIE) silicon microchannel cold plates $(9 \mathrm{~mm} \times 9 \mathrm{~mm} \times 0.5$ $\mathrm{mm}$ ) with $50 \mu \mathrm{m} \times 400 \mu \mathrm{m}$ microchannels, shown in Fig. 5(a), developed in cleanroom facilities. The Si-chips are bonded to a 3-layer laser-cut PMMA manifold that spreads evenly deionized water to the microchannel, as illustrated in Fig. 5(b). The flow rate can be regulated by a micro-pump (with less than $1 \mathrm{~W}$ power requirements), directly controlled by the drive board. Details on the fabrication process of the Si cold plates and the PMMA manifold, along with a thorough hydraulic and thermal analysis can be found in [20].

\section{EXPERIMENTAL EVALUATION}

The performance of the developed magnetic-less DC/DC converter was thoroughly investigated with the experimental setup depicted in Fig. 6. The main power loop is comprised by a low voltage/high current $1.2 \mathrm{~kW}$ DC power supply, the $10 \mathrm{X}$ converter prototype and a resistive load of $550 \Omega$. The flow rate of the developed microchannel heat sink was regulated through a pressure controller and a pressurized water reservoir. Real time monitoring of the temperature of each individual transistor was achieved through TI Code Composer Studio (CCS) platform. The converter input and output voltage and

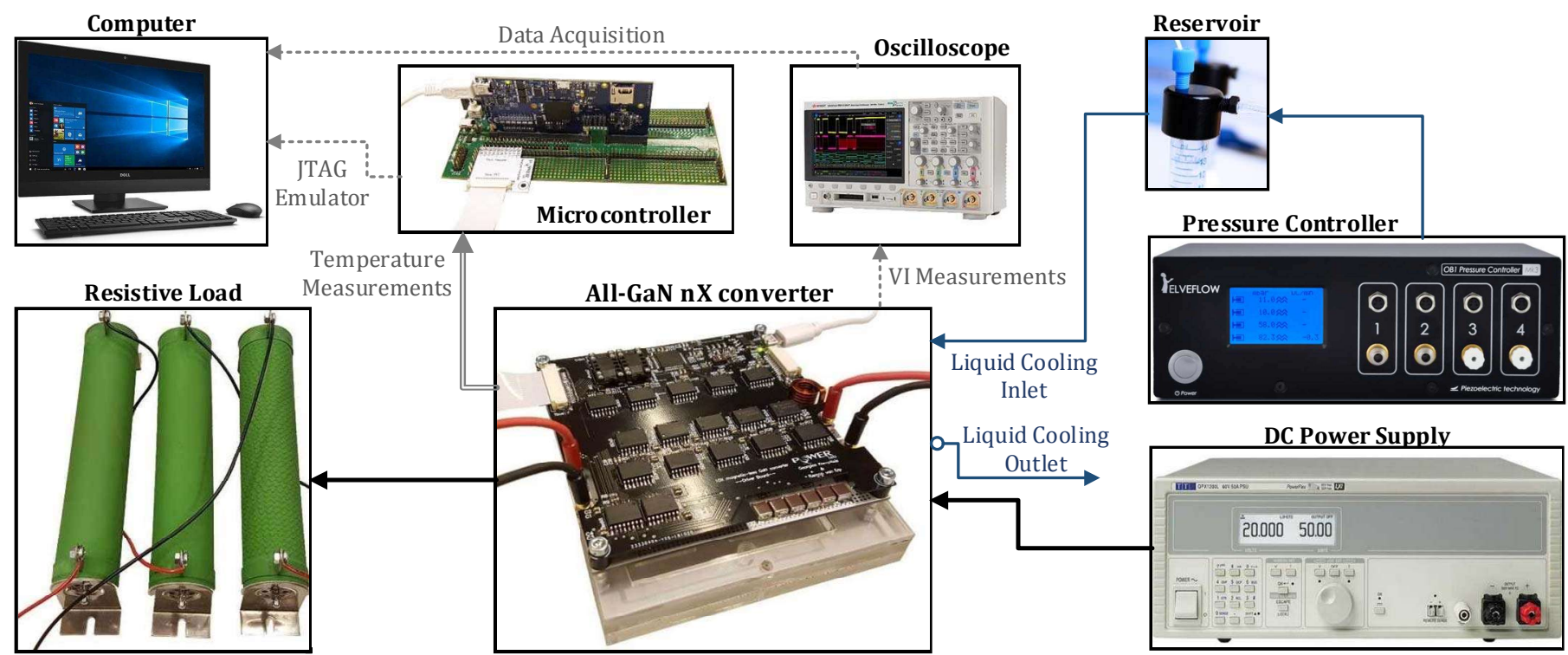

Fig. 6. Block diagram illustrating the experimental setup for evaluating the performance of the developed magnetic-less converter prototype. 
current values were continuously recorded by multimeters and their waveforms by a $350 \mathrm{MHz}$ digital oscilloscope.

The experiments were performed by gradually increasing the transferred power up to the maximum value of $1.2 \mathrm{~kW}$, limited only by the DC power supply. To first validate the stress of the devices located in different cells, the drain-tosource voltage waveforms of $Q_{a}$ in the $1^{\text {st }}$ and $2^{\text {nd }}$ cell were recorded and are presented in Fig. 7, while the converter was operating at low power $\left(V_{\text {in }}=30 \mathrm{~V}, P_{\text {out }}=500 \mathrm{~W}, R_{\text {load }}=180\right.$ $\Omega)$. The voltage waveforms of the $3^{\text {rd }}$ cell capacitors, $C_{a}(3)$ and $C_{b}(3)$, are also included in the same figure, revealing their low voltage ripple. The input and output voltage and current

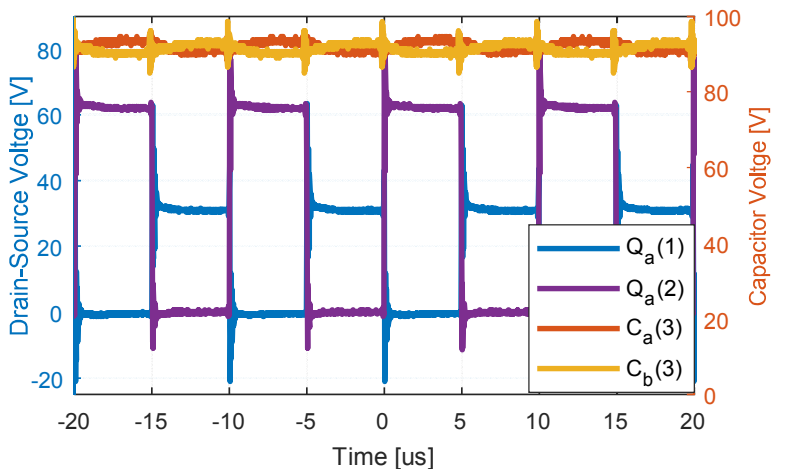

Fig. 7. Voltage stress of the transistors $Q_{a}(1), Q_{a}(2)$ and voltage across the switching capacitors of the 3 rd cell, $C_{a}(3)$ and $C_{b}(3)$.

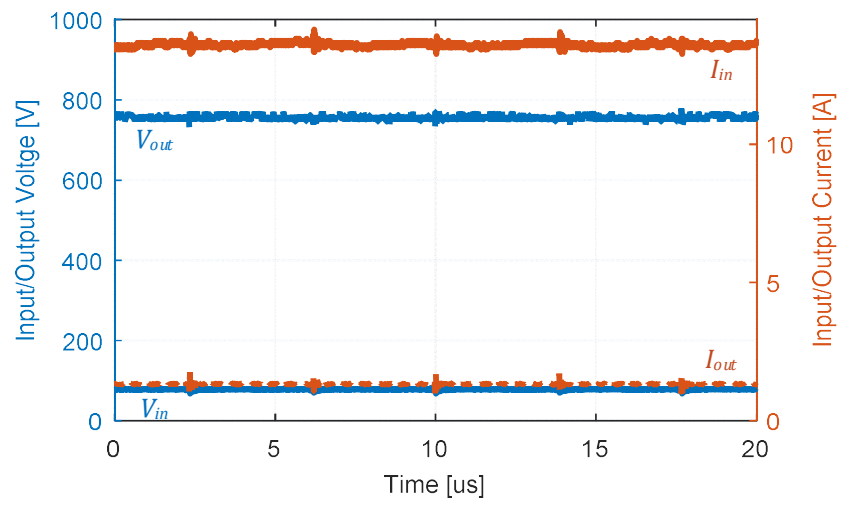

(a)

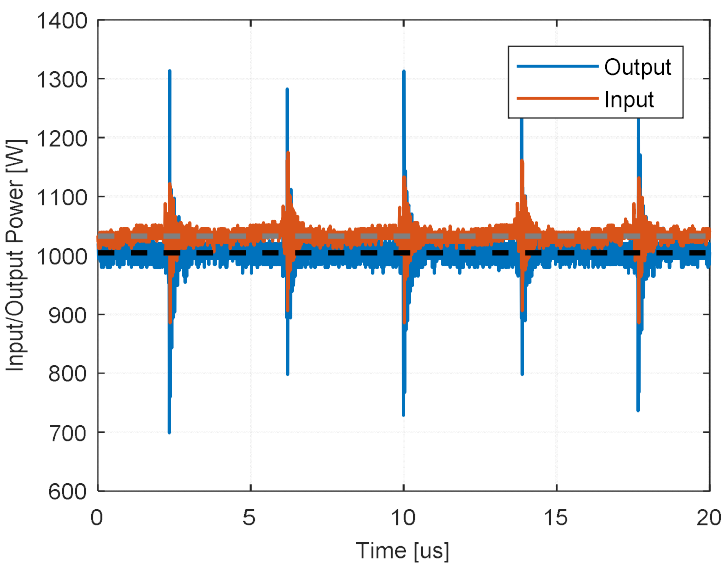

(b)

Fig. 8. Experimental results of the developed $10 \mathrm{X}$ converter operating at $V_{\text {in }}=$ $78 \mathrm{~V}$ and $P_{\text {out }}=1 \mathrm{~kW}$. The microfluidic heat sink was operated at 0.5 bar corresponding to a flow rate of $0.96 \mathrm{~mL} / \mathrm{s}$. (a) Input and output voltage and current waveforms and (b) input and output power. waveforms at $F_{s w}=130 \mathrm{kHz}, V_{\text {in }}=78 \mathrm{~V}$ and $P_{\text {out }}=1 \mathrm{~kW}$ are depicted in Fig. 8(a), from which, the almost ripple-less output voltage is evident, despite the small value of the output capacitance. Fig. 8(b) shows the instantaneous input and output power waveforms along with their average values.

The efficiency of the system was calculated, taking into account measurements from three different sources: the multimeters, the oscilloscope waveforms and the indications of the power supply. The plot of the efficiency over operating power is presented in Fig. 9, in which, the error bars represent the mismatch between the different measurement equipment. The overall efficiency of $96 \%$ for the entire power range implies that the efficiency per cell is greater than $99.2 \%$. The decoupling of the efficiency value from the operating point is a distinct characteristic and advantage of magnetic-less converters against conventional DC/DC converters with magnetic components. A small degradation of the efficiency curve is expected in higher current densities due to the increase of the on-state resistance of the power devices with higher temperatures [21], [22]. And this is where the full potential of the micro-fluidic cooling system is revealed; keeping the transistors' junction temperature low enhances the performance and reliability of the system.

To evaluate the effectiveness of the developed nearjunction heat sink, the $\mathrm{nX}$ converter prototype was operated at a fixed power of $1 \mathrm{~kW}$ and the temperature measurements from all thermocouples were collected and plotted over time in Fig. 10. After 3 min of operation the power was reduced to zero and the system was let to cool-down. The pressure drop of the liquid cooling system was 1 Bar, corresponding to a flow rate of $1.56 \mathrm{~mL} / \mathrm{s}$.

Even at $1 \mathrm{~kW}$, the average temperature rise was just $9.16^{\circ} \mathrm{C}$ (from an ambient temperature of $25^{\circ} \mathrm{C}$ ). The temperature rise per input power of the converter was $0.01 \mathrm{~K} / \mathrm{W}$, which theoretically allows the converter to operate up to $7 \mathrm{~kW}$ with a temperature rise no greater than $70^{\circ} \mathrm{C}$, leading in a projected power density of $26.9 \mathrm{~W} / \mathrm{cm}^{3}$ [20]. Another significant advantage of the liquid cooling approach is the short time to reach thermal stability (less than $3 \mathrm{~min}$ in this experiment). To better illustrate the distribution of heat on the PCB and the power dissipation among the power devices a heat-map of the converter under thermal stability was constructed based on the integrated thermocouple reading of each transistor, which is presented in Fig. 11(a). As expected, the transistors of the top

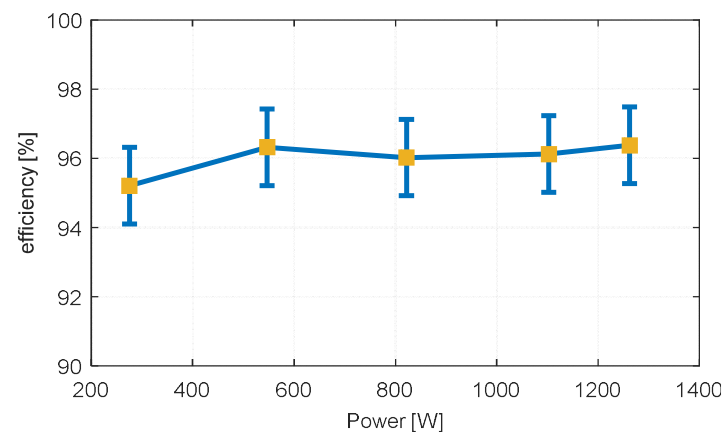

Fig. 9. Experimentally extracted efficiency curve over operating power of the $10 \mathrm{x}$ converter demonstrator. For these measurements the liquid cooling system pressure was set at 1 Bar, corresponding to a flow rate of $1.56 \mathrm{~mL} / \mathrm{s}$. 
and bottom rail, $Q_{a}$, show higher power losses, compared to the transistors in the bridge leg configuration, as a result of their higher on-state resistance. It is also evident that the devices $Q_{P / N}(5)$ of the last cell retain a low temperature, due to their lower current stress.

The only measurements that seem in disagreement with the theoretical analysis of Section II are the temperature values of $Q_{a / b}(1)$ : These transistors were subjected to lower voltage stress but show the highest temperature. The reason for this mismatch is that the thermocouples of $Q_{a}(1)$ and $Q_{b}(1)$ were in close proximity to the external air core inductor, $L_{s w}$, which heats up under a large input current. This side-effect of the soft switching inductor is also evident by the thermal image taken from the top side of the converter (Fig. 11(b)) that shows the heat spreading around the inductor. It is, thus, evident that optimum performance can be achieved by removing the $L_{s w}$, and tuning the switching frequency to achieving ZCS based solely on the circuits parasitic inductances.

\section{CONCLUSIONS}

In this work a GaN-based magnetic-less DC/DC converter with large step-up ratio has been developed and experimentally validated. The converter exhibited great efficiency $(>99.2 \%$ per cell and $96 \%$ for $10 \mathrm{X}$ conversion) with almost no dependence
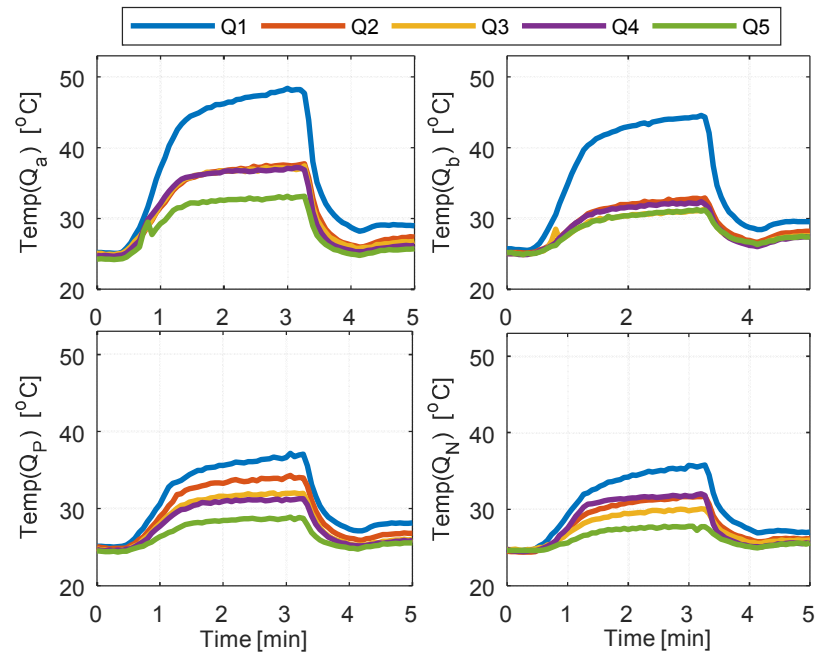

Fig. 10. Temperature increase of each individual transistor over time, when the converter operates at $1 \mathrm{~kW}$ and the microchannel heat sink flow rate is 1.56 $\mathrm{mL} / \mathrm{s}$.

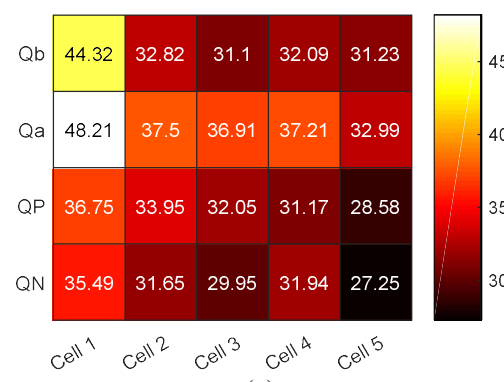

(a)

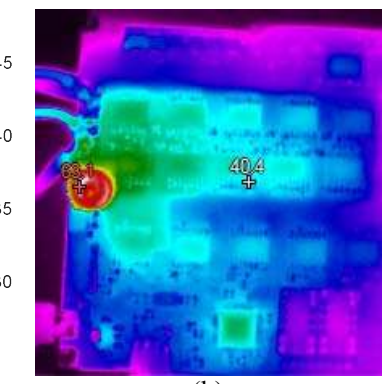

(b)
Fig. 11. (a) Heat-map of the $\mathrm{nX}$ converter operating at $1 \mathrm{~kW}$ and a flow rate of $1.56 \mathrm{~mL} / \mathrm{s}$ for the liquid cooling heat sink. The values on the heat-map represent the case temperature of each individual transistor at steady state conditions (when thermal stability has been reached). (b) Thermal image sowing that the hottest part of the converter is the soft switching inductor, $L_{s w}$. on the load. The developed prototype was tested only at a fraction of its power capability, limited by the power supply, and already reached $4.62 \mathrm{~W} / \mathrm{cm}^{3}$, a record power density for such a high step-up DC/DC converter.

The enabling factor for the miniaturization of the converter and exceptional performance throughout the entire power range was the use of a customized manifold microchannel heat sink that exhibited higher cooling capability compared to conventional heat sinks. The low pumping requirements favors the use of a low-power-consumption micropumps that can be directly integrated on the manifold. More importantly, such near-junction heat sinks can be customized for any GaN-based converter with ultra-high power density requirements.

The combination of $\mathrm{GaN}$ technology and micro-fluidic cooling in magnetic-less converter topologies can have a significant impact on future power conversion applications.

\section{REFERENCES}

[1] E. A. Jones, F. F. Wang, and D. Costinett, "Review of Commercial GaN Power Devices and GaN-Based Converter Design Challenges," IEEE Journal of Emerging and Selected Topics in Power Electronics, vol. 4, no. 3, pp. 707-719, Sep. 2016.

[2] J. Ma, G. Santoruvo, P. Tandon, and E. Matioli, "Enhanced Electrical Performance and Heat Dissipation in AlGaN/GaN Schottky Barrier Diodes Using Hybrid Tri-anode Structure," IEEE Transactions on Electron Devices, pp. 1-6, 2016.

[3] J. Ma and E. Matioli, "Slanted Tri-Gates for High-Voltage GaN Power Devices," IEEE Electron Device Letters, vol. 38, no. 9, pp. 1305-1308, Sep. 2017.

[4] Marian K. Kazimierczuk, High-frequency magnetic components, Second edition. Chichester: John Wiley, 2014.

[5] F. Z. Peng, "A generalized multilevel inverter topology with self voltage balancing," IEEE Transactions on Industry Applications, vol. 37, no. 2, pp. 611-618, Mar. 2001.

[6] Fang Zheng Peng, Fan Zhang, and Zhaoming Qian, "A magnetic-less DC-DC converter for dual-voltage automotive systems," IEEE Transactions on Industry Applications, vol. 39, no. 2, pp. 511-518, Mar. 2003.

[7] K.-Y. Lee and Y.-S. Lai, "A novel magnetic-less bi-directional dc-dc converter," in 30th Annual Conference of IEEE Industrial Electronics Society, 2004. IECON 2004, 2004, vol. 2, pp. 1014-1017 Vol. 2.

[8] F. Z. Peng and Fan Zhang, "A Novel compact DC/DC converter for 42 V systems," in IEEE 34th Annual Conference on Power Electronics Specialist, 2003. PESC '03, Acapulco, Mexico, 2002, pp. 143-148.

[9] Zhiguo Pan, Fan Zhang, and F. Z. Peng, "Power losses and efficiency analysis of multilevel dc-dc converters," in Twentieth Annual IEEE Applied Power Electronics Conference and Exposition, 2005. APEC 2005., Austin, TX, USA, 2005, vol. 3, pp. 1393-1398.

[10] Fan Zhang, Lei Du, Fang Zheng Peng, and Zhaoming Qian, "A New Design Method for High-Power High-Efficiency Switched-Capacitor DC-DC Converters," IEEE Transactions on Power Electronics, vol. 23, no. 2, pp. 832-840, Mar. 2008.

[11] F. H. Khan and L. M. Tolbert, "A Multilevel Modular CapacitorClamped DC-DC Converter," IEEE Transactions on Industry Applications, vol. 43, no. 6, pp. 1628-1638, 2007.

[12] F. H. Khan and L. M. Tolbert, "5 kW Multilevel DC-DC Converter for Hybrid Electric and Fuel Cell Automotive Applications," in IEEE Industry Applications Annual Meeting, New Orleans, LA, USA, 2007, pp. 628-635.

[13] F. H. Khan and L. M. Tolbert, "Generating isolated outputs in a multilevel modular capacitor clamped dc-dc converter (MMCCC) for hybrid electric and fuel cell vehicles," in 2008 IEEE Power Electronics Specialists Conference, Rhodes, Greece, 2008, pp. 967973. 
[14] F. H. Khan and L. M. Tolbert, "Multiple Load-Source Integration in a Multilevel Modular Capacitor Clamped DC-DC Converter Featuring Fault Tolerant Capability," in APEC 07 - Twenty-Second Annual IEEE Applied Power Electronics Conference and Exposition, Anaheim, CA, USA, 2007, pp. 361-367.

[15] W. Qian, D. Cao, J. G. Cintron-Rivera, M. Gebben, D. Wey, and F. Z. Peng, "A Switched-Capacitor DC-DC Converter With High Voltage Gain and Reduced Component Rating and Count," IEEE Transactions on Industry Applications, vol. 48, no. 4, pp. 1397-1406, Jul. 2012.

[16] A. Jafari and E. Matioli, "High Step-Up High-Frequency ZeroVoltage Switched GaN-Based Single-Stage Isolated DC-DC Converter for PV Integration and Future DC Grids," in PCIM Europe 2018; International Exhibition and Conference for Power Electronics, Intelligent Motion, Renewable Energy and Energy Management, 2018, pp. 1-6.

[17] M. L. Gebben, J. G. Cintron-Rivera, W. Qian, D. Cao, X. Pei, and F. Z. Peng, "A zero-current-switching multilevel switched capacitor DC-
DC converter," in IEEE Energy Conversion Congress and Exposition, Phoenix, AZ, USA, 2011, pp. 1291-1295.

[18] D. Cao and F. Z. Peng, "A family of zero current switching switchedcapacitor dc-dc converters," in 2010 Twenty-Fifth Annual IEEE Applied Power Electronics Conference and Exposition (APEC), Palm Springs, CA, USA, 2010, pp. 1365-1372.

[19] D. B. Tuckerman and R. F. W. Pease, "High-performance heat sinking for VLSI," IEEE Electron Device Letters, vol. 2, no. 5, pp. 126-129, May 1981.

[20] R. van Erp, G. Kampitsis, and E. Matioli, "A manifold microchannel heat sink for ultra-high power density liquid-cooled converters." 2019 IEEE Applied Power Electronics Conference and Exposition, Anaheim, CA, USA, in press.

[21] GaN Systems, "Top-side cooled 100 V E-mode GaN transistor," GS61008T, Preliminary Datasheet / Rev 180420.

[22] GaN Systems, "Top-side cooled 650 V E-mode GaN transistor," GS66506T, Preliminary Datasheet / Rev 180422. 